\title{
Mananoligossacarídeos em dietas para frangos de corte
}

\author{
Mannanoligosaccharides in diets for broilers
}

\section{Nei André Arruda Barbosa' ${ }^{\mathrm{I}}$ Nilva Kazue Sakomura ${ }^{\mathrm{II}}$ Edgar Orlando Oviedo-Rondón ${ }^{\mathrm{III}}$ Melina Aparecida Bonato ${ }^{\mathrm{I}}$ Iris Mayumi Kawauchi ${ }^{\mathrm{I}}$ Ronnie Luiz Dari ${ }^{\mathrm{IV}}$ João Batista Kochenborger Fernandes ${ }^{\mathrm{V}}$}

RESUMO

Objetivou-se avaliar dietas contendo mananoligossacarídeos (MOS) como aditivo alternativo aos promotores de crescimento por meio do estudo da morfometria do intestino e do desempenho de frangos de corte. Para tanto, 1280 pintos de corte foram distribuídos em delineamento inteiramente casualizado com quatro tratamentos (controle negativo, CN: dieta isenta de antibiótico; controle positivo, CP: dieta contendo antibiótico e duas dietas, MOS 1 e MOS 2, nas quais foram adicionadas ao $\mathrm{CN}$ duas fontes distintas de $M O S)$ e oito repetições, sendo a unidade experimental composta por 40 aves. Para submeter as aves ao desafio sanitário, foi formulada uma dieta basal com milho, farelo de soja e farinha de carne e ossos. Adotou-se cama reutilizada, limpeza dos bebedouros duas vezes por semana e oferta semanal de água contaminada com cama. Foram avaliadas altura de vilo e profundidade de cripta do duodeno, jejuno e íleo, consumo da dieta, peso médio, ganho de peso e conversão alimentar das aves. Houve melhora na profundidade de cripta no jejuno e na altura de vilo no íleo das aves alimentadas com dietas contendo MOS. A adição de MOS, independente da fonte, resultou em melhor conversão alimentar em relação às aves do $\mathrm{CN}$, sendo similares às aves do CP. Os mananoligossacarídeos podem ser utilizados como aditivo alternativo aos promotores de crescimento em dietas para frangos de corte, porém, dependendo da fonte, esta pode acarretar em pequenas diferenças no desempenho das aves.

Palavras-chave: aditivo, aves, prebióticos, promotor de crescimento, saúde intestinal.

\begin{abstract}
This study aimed to evaluate mannan oligosaccharides (MOS) as an alternative additive to growth promoters in broiler diets by studying the morphology of the intestine and the performance. For this purpose, 1280 broiler chicks were distributed in a completely randomized design with four treatments (negative control, NC: diet free of antibiotics; positive control, PC: diet with antibiotic and two diets, MOS 1 and MOS 2, in which were added to NC two distinct sources of $M O S)$ and eight repetitions, and the experimental unit consisted of 40 birds. To submit birds to the challenge, a basal diet was formulated with corn, soybean meal and meat and bones meal, was adopted used litter, cleaning of water troughs twice a week and were offered weekly water contaminated with litter. The variables evaluated were villus height and crypt depth of duodenum, jejunum and ileum, feed intake, weight, body weight gain and feed conversion ratio. There was improvement in crypt depth in jejunum and in villus height in ileum of birds fed diets containing MOS. The addition of MOS, regardless of source, resulted in improvement in feed conversion ratio than birds of NC, and were similar to the birds of PC. The mannan oligosaccharides can be used as an alternative additive to growth promoters in diets for broiler chickens, but depending on the source, this can result in small differences in bird performance.
\end{abstract}

Key words: additive, birds, growth promoter, prebiotics, intestinal health.

\footnotetext{
'Programa de Pós-graduação em Zootecnia, Faculdade de Ciências Agrárias e Veterinárias (FCAV), Universidade Estadual Paulista (UNESP), Jaboticabal, SP, Brasil.

"Departamento de Zootecnia, FCAV, UNESP, Via de Acesso Prof. Paulo Donato Castellane, s/n, 14884-900, Jaboticabal, SP, Brasil. E-mail: sakomura@fcav.unesp.br. Autor para correspondência.

IIIDepartment of Poultry Science, North Carolina State University, Raleigh, North Carolina.

${ }^{\mathrm{IV}}$ Biorigin-Zilor, São Paulo, SP, Brasil.

${ }^{\mathrm{v} C e n t r o ~ d e ~ A g r i c u l t u r a, ~ F C A V, ~ U N E S P, ~ J a b o t i c a b a l, ~ S P, ~ B r a s i l . ~}$
} 


\section{INTRODUÇÃO}

As evidências dos efeitos residuais e da resistência bacteriana nos animais vêm motivando o mercado consumidor a impor restrições ao uso de antibióticos e quimioterápicos em dietas para aves e suínos com intuito de atuarem como promotores de crescimento. Nesse contexto, é crescente a demanda por produtos alternativos, como os prebióticos, os quais modulam a microbiota nativa do hospedeiro, favorecendo os microrganismos benéficos do trato gastrintestinal, o que pode proporcionar melhora no desempenho animal (FAIRCHILD et al., 2001; PARKS et al., 2001).

GIBSON e ROBERFROID (1995) definiram prebióticos como sendo ingredientes alimentares que não são digeridos na porção proximal do trato gastrintestinal de animais monogástricos e são benéficos ao hospedeiro por estimular, seletivamente, o crescimento e/ou atividade de um limitado número de microrganismos no cólon, os quais proporcionam um ambiente intestinal saudável.

Os mananoligossacarídeos modulam a flora intestinal, reduzem a taxa de renovação da mucosa intestinal (turnover) e estimulam o sistema imune (ALBINO et al., 2006), o que melhora e protege a mucosa, reduzindo lesões intestinais e propiciando maior altura dos vilos e profundidade de cripta (PELICANO et al., 2005). Tais propriedades podem melhorar o desempenho animal e diminuir a mortalidade de frangos de corte.

Diante do exposto, a presente pesquisa teve por objetivo avaliar dietas contendo MOS como aditivo alternativo aos promotores de crescimento por meio do estudo da morfometria do intestino e do desempenho de frangos de corte.

\section{MATERIAL E MÉTODOS}

Foi realizado um ensaio de desempenho com duração de 42 dias, no qual foram criados 1280 pintos de corte machos da linhagem $\mathrm{Cobb}^{\circledR}$, com um dia de idade. Para formação das unidades experimentais, as aves foram pesadas individualmente e distribuídas de forma que todas as parcelas apresentassem peso médio similar. O delineamento experimental foi inteiramente casualizado com quatro tratamentos e oito repetições de 40 aves cada, totalizando 32 unidades experimentais. Os tratamentos consistiram de um controle negativo (CN, dieta isenta de antibiótico), um controle positivo (CP, dieta com antibiótico, virginiamicina 50\%, 40g tonelada $^{-1}$ de alimento) e duas dietas nas quais foram adicionadas ao $\mathrm{CN}$ duas fontes distintas de MOS, denominadas de MOS 1e MOS 2.
Os mananoligossacarídeos avaliados foram originários de cepas da levedura Saccharomyces cerevisiae, porém obtidos por diferentes processos. $\mathrm{O}$ MOS 1 foi obtido pela reprodução da levedura em meio aeróbico, com o objetivo principal de produzir biomassa de levedura para a produção de MOS e outras frações da célula para serem usados na alimentação animal. Já o MOS 2 foi produzido a partir da levedura correspondente ao subproduto da indústria de fermentação alcoólica. Os mananoligossacarídeos avaliados possuíam as seguintes características: MOS 1-27\% de proteína; $6,20 \%$ de umidade; $25,30 \%$ de mananos; 34,60\% de glucanos; $\mathrm{pH}$ de 5,50 e densidade de $535 \mathrm{~g} / \mathrm{l}$; MOS 2-35,71\% de proteína; 5,54\% de umidade; $15,20 \%$ de mananos; $22,50 \%$ de glucanos; $\mathrm{pH}$ de 7,19 e densidade de $510 \mathrm{~g}^{-1}$.

Foram formuladas dietas com milho e farelo de soja (Tabela 1), sendo a composição dos alimentos e os níveis nutricionais considerados nas formulações baseados nas tabelas brasileiras de aves e suínos (ROSTAGNO et al., 2005). O antibiótico e as fontes de MOS foram adicionados em substituição ao inerte. Alimento e água foram fornecidos ad libitum.

Com intuito de reproduzir as condições de campo e proporcionar desafio às aves, foi utilizada na formulação das dietas farinha de carne e ossos (45\% de proteína bruta), adotou-se cama reutilizada de lotes comerciais, os bebedouros foram higienizados apenas duas vezes por semana e as aves foram submetidas à ingestão de água contaminada com cama uma vez por semana. Para tanto, procedeu-se à mistura de um quilograma de cama com quatro litros de água, sendo a mistura filtrada e, após as aves passarem por jejum hídrico de duas horas, fora disponibilizada nos bebedouros.

Aos 21 e 42 dias de idade das aves, foi realizada avaliação morfométrica do intestino destas e, para isso, uma ave por unidade experimental foi sacrificada após jejum de 12 horas. As aves foram insensibilizadas por meio de gás carbônico e, após, foram extraídas amostras de, aproximadamente, dois centímetros de comprimento de cada um dos segmentos do intestino delgado: duodeno (a partir do piloro até a porção distal da alça duodenal); jejuno (a partir da porção distal da alça duodenal até o divertículo de Meckel) e íleo (porção anterior aos cecos). Foi feita abertura dos segmentos no sentido longitudinal, sendo estes estirpados e imediatamente fixados em solução de Bouin por 24 horas. As amostras foram lavadas em álcool $70 \%$ e, posteriormente, foram realizadas desidratações em série crescente de alcoois. Foram diafanizadas em xilol, incluídas em parafina e feitos cortes histológicos semi-seriados de $5 \mu \mathrm{m}$ de espessura e corados com hematoxilina e eosina, segundo 
Tabela 1 - Composição centesimal e níveis nutricionais calculados das dietas inicial (1 a 21 dias), crescimento ( 22 a 33 dias) e final ( 34 a 42 dias) para frangos de corte.

\begin{tabular}{|c|c|c|c|}
\hline Ingredientes (\%) & Inicial $^{1}$ & Crescimento $^{1}$ & Final $^{1}$ \\
\hline Milho & 63,58 & 64,50 & 67,13 \\
\hline Farelo de soja $45 \%$ & 29,29 & 27,54 & 24,92 \\
\hline Farinha de carne e ossos & 3,00 & 2,50 & 2,50 \\
\hline Óleo degomado de soja & 1,03 & 2,43 & 2,67 \\
\hline Calcário & 0,74 & 0,72 & 0,67 \\
\hline Fosfato bicálcico & 0,64 & 0,68 & 0,53 \\
\hline Inerte $^{2}$ & 0,50 & 0,50 & 0,50 \\
\hline Sal comum & 0,45 & 0,43 & 0,39 \\
\hline L-Lisina $78 \%$ & 0,27 & 0,24 & 0,25 \\
\hline DL-Metionina $99 \%$ & 0,26 & 0,24 & 0,22 \\
\hline L-Treonina & 0,08 & 0,06 & 0,06 \\
\hline Suplemento vitamínico ${ }^{3}$ & 0,10 & 0,10 & 0,10 \\
\hline Suplemento mineral ${ }^{4}$ & 0,05 & 0,05 & 0,05 \\
\hline \multicolumn{4}{|c|}{--_emposição nutricional-- } \\
\hline EMA (kcal/kg) & 3000 & 3100 & 3150 \\
\hline $\mathrm{PB}(\%)$ & 20,50 & 19,50 & 18,50 \\
\hline Lisina digestível (\%) & 1,15 & 1,07 & 1,02 \\
\hline Met.+cist. digestível (\%) & 0,81 & 0,77 & 0,73 \\
\hline Metionina digestível (\%) & 0,54 & 0,51 & 0,47 \\
\hline Treonina digestível (\%) & 0,74 & 0,69 & 0,66 \\
\hline $\mathrm{Ca}(\%)$ & 0,88 & 0,82 & 0,76 \\
\hline $\mathrm{P}$ disponível (\%) & 0,44 & 0,41 & 0,38 \\
\hline
\end{tabular}

${ }^{1}$ Adição de MOS 1 ou MOS 2: 1,5; 1,0 e 0,5kg tonelada ${ }^{-1}$ de dieta para as fases inicial, crescimento e final, respectivamente. Adição do antibiótico virginiamicina 50\%: $40 \mathrm{~g}^{\text {tonelada }}{ }^{-1}$ de alimento para todas as fases. ${ }^{2}$ Areia lavada. ${ }^{3}$ Adição por quilograma de produto: ácido fólico $1000 \mathrm{mg}$, ácido pantotênico $15000 \mathrm{mg}$, antioxidante $0,5 \mathrm{~g}$, niacina $40000 \mathrm{mg}$, selênio $300 \mathrm{mg}$, biotina $60 \mathrm{mg}$, vit B1 $1800 \mathrm{mg}$, vit B12 $12000 \mathrm{mg}$, vit B2 $6000 \mathrm{mg}$, vit B6 $2800 \mathrm{mg}$, vit D3 2000000UI, vit E $15000 \mathrm{mg}$, vit K3 $1800 \mathrm{mg}$. ${ }^{4}$ Adição por quilograma de produto:Mn $150,000 \mathrm{mg}, \quad \mathrm{Zn}$ 100,000mg, Fe 100,000mg, Cu 16,000mg, I 1,500mg.

metodologia de BEHMER et al. (1976). As lâminas foram preparadas com Bálsamo do Canadá e fotografadas em lupa (LEICA DM 2500) com lente objetiva com aumento de cinco vezes, utilizando o programa LEICA QWin V3. As análises morfométricas da mucosa intestinal em microscopia de luz foram realizadas com auxílio do programa Image $\mathbf{J}^{\oplus}$ (RASBAND, 2004). As características avaliadas foram: altura de vilos e profundidade de cripta, sendo consideradas 30 leituras de cada repetição/região intestinal/variável.

Aos 21, 33 e 42 dias de idade, as aves e as sobras de alimento foram pesadas para determinação das características de desempenho: peso médio $\left(\mathrm{kg} \mathrm{ave}^{-1}\right)$, ganho de peso $\left(\mathrm{kg} \mathrm{ave}^{-1}\right)$, consumo médio da dieta $(\mathrm{kg}$ $a^{-1} e^{-1}$ e conversão alimentar $\left(\mathrm{kg} \mathrm{kg}^{-1}\right)$. O consumo da dieta pelas aves foi corrigido pela mortalidade conforme SAKOMURA\& ROSTAGNO (2007).
As análises estatísticas foram realizadas com auxílio do software SAS (2001). Foram atendidas as pressuposições de normalidade dos erros e homogeneidade de variância pelos testes de Cramervon Mises e Brown \& Forsythe's, respectivamente. Os dados foram submetidos à análise de variância pelo procedimento GLM e as médias comparadas pelo teste de Duncan, considerando nível de significância de 5\%.

\section{RESULTADOS E DISCUSSÃO}

Houve efeito significativo das dietas experimentais sobre as características morfométricas do intestino de frangos de corte somente aos 42 dias de idade (Tabela 2). As aves que consumiram dietas contendo MOS e o CP apresentaram maior $(\mathrm{P}<0,05)$ profundidade de cripta na porção jejunal em comparação com o CN. Verificou-se, também, maior $(\mathrm{P}<0,05)$ altura de vilo no segmento ileal de frangos que receberam a dieta MOS 2 em relação aos demais tratamentos.

Tais incrementos são importantes, pois sabe-se que as vilosidades desempenham importante papel no processo de absorção de nutrientes no intestino delgado, sendo que o aumento desta estrutura proporciona maior superfície de contato e, como consequência, pode haver aumento na absorção dos nutrientes no lúmen intestinal (GARTNER \& HIATT, 2001). Pequenos incrementos, como os verificados no presente estudo, são fundamentais para manutenção da integridade da mucosa intestinal, uma vez que determinam a dimensão da superfície de contato do intestino e, consequentemente, a capacidade digestiva e absortiva do segmento (BOLELI et al., 2002).

SPRING et al. (2000) e SANTIN et al. (2001) verificaram maior altura de vilo no duodeno com a adição de prebiótico à dieta de frangos de corte aos sete dias de idade e atribuíram o resultado ao efeito trófico do prebiótico sobre a mucosa intestinal. Porém, é possível que os benefícios advindos da inclusão de MOS à dieta de frangos observados no presente estudo estejam relacionados, principalmente, à modulação da microbiota intestinal, uma vez que os resultados de morfometria não foram condinzentes com aqueles verificados para as características de desempenho das aves.

Constatou-se que, na fase inicial (um a 21 dias de idade), as aves alimentadas com a dieta CP apresentaram maior $(\mathrm{P}<0,05)$ consumo em relação àquelas arraçoadas com a dieta MOS 2 (Tabela 3). Já os frangos que consumiram as dietas $\mathrm{CP}$ e MOS 2 apresentaram melhor conversão alimentar em relação aos animais do $\mathrm{CN}$. Os resultados da fase de 
Tabela 2 - Profundidade de cripta (PC) e altura de vilos (AV) dos segmentos duodenal, jejunal e ileal do intestino de frangos de corte submetidos às dietas experimentais.

\begin{tabular}{|c|c|c|c|c|c|c|c|}
\hline \multirow{2}{*}{$\begin{array}{l}\text { Segmento } \\
\text { intestinal }\end{array}$} & \multirow{2}{*}{ Morfometria } & \multicolumn{4}{|c|}{ 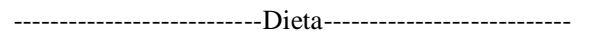 } & \multirow{2}{*}{ Probabilidade } & \multirow{2}{*}{$\mathrm{CV}(\%)$} \\
\hline & & $\mathrm{CN}$ & $\mathrm{CP}$ & MOS 1 & MOS 2 & & \\
\hline \multicolumn{8}{|c|}{ 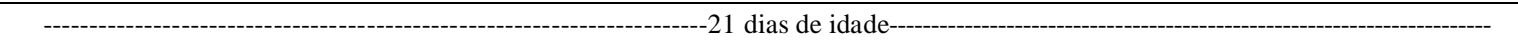 } \\
\hline \multirow{2}{*}{ Duodeno } & $\mathrm{PC}, \mathrm{mm}$ & 0,259 & 0,242 & 0,289 & 0,304 & 0,101 & 18,26 \\
\hline & $\mathrm{AV}, \mathrm{mm}$ & 1,199 & 1,219 & 1,212 & 1,179 & 0,959 & 12,08 \\
\hline \multirow{2}{*}{ Jejuno } & $\mathrm{PC}, \mathrm{mm}$ & 0,217 & 0,217 & 0,224 & 0,184 & 0,138 & 15,98 \\
\hline & $\mathrm{AV}, \mathrm{mm}$ & 0,898 & 0,900 & 0,905 & 0,918 & 0,992 & 14,42 \\
\hline \multirow{2}{*}{ Íleo } & $\mathrm{PC}, \mathrm{mm}$ & 0,188 & 0,179 & 0,187 & 0,168 & 0,073 & 8,65 \\
\hline & $\mathrm{AV}, \mathrm{mm}$ & 0,663 & 0,715 & 0,751 & 0,729 & 0,113 & 9,33 \\
\hline & & & -----42 & e idade-- & & & - \\
\hline \multirow{2}{*}{ Duodeno } & $\mathrm{PC}, \mathrm{mm}$ & 0,304 & 0,267 & 0,297 & 0,309 & 0,593 & 16,58 \\
\hline & $\mathrm{AV}, \mathrm{mm}$ & 1,413 & 1,258 & 1,363 & 1,464 & 0,183 & 9,47 \\
\hline \multirow{2}{*}{ Jejuno } & $\mathrm{PC}, \mathrm{mm}$ & $0,176^{\mathrm{b}}$ & $0,242^{\mathrm{a}}$ & $0,238^{\mathrm{a}}$ & $0,222^{\mathrm{a}}$ & 0,005 & 11,01 \\
\hline & $\mathrm{AV}, \mathrm{mm}$ & 0,853 & 1,152 & 1,137 & 1,212 & 0,091 & 18,62 \\
\hline \multirow{2}{*}{ Íleo } & $\mathrm{PC}, \mathrm{mm}$ & 0,171 & 0,162 & 0,182 & 0,180 & 0,719 & 17,55 \\
\hline & $\mathrm{AV}, \mathrm{mm}$ & $0,797^{\mathrm{b}}$ & $0,796^{\mathrm{b}}$ & $0,883^{\mathrm{b}}$ & $1,066^{\mathrm{a}}$ & 0,007 & 12,30 \\
\hline
\end{tabular}

${ }^{a, b}$ Médias com letras iguais nas linhas não diferem entre si pelo teste de Duncan $(\mathrm{P}>0,05)$.

crescimento (22 a 33 dias de idade) reportam efeito significativo somente para conversão alimentar e, assim como na fase anterior, os frangos alimentados com a dieta CP e MOS 2 apresentaram melhor $(\mathrm{P}<0,05)$ conversão em relação ao grupo $\mathrm{CN}$. Foi observado também que as aves do $\mathrm{CP}$ apresentaram melhor $(\mathrm{P}<0,05)$ conversão alimentar em relação àquelas do tratamento MOS 1. Tanto na fase final quanto no período total da criação, de forma geral, a dieta MOS 1 proporcionou melhora $(\mathrm{P}<0,05)$ no peso médio, no ganho de peso e na conversão alimentar das aves. Na fase final, especificamente, ao contrário do observado nos períodos precedentes, a dieta MOS 1 proporcionou maior ganho de peso e melhor conversão alimentar das aves em relação aos demais tratamentos.

Os resultados observados no presente estudo indicam que existem diferenças entre as fontes de MOS avaliadas. A dieta MOS 2 proporcionou melhor conversão alimentar nas fases inicial e de crescimento de frangos de corte, apesar de possuir menor teor de mananos e glucanos e ser um subproduto da indústria de fermentação alcoólica. Porém, ao considerar a fase final e o período total de criação, observa-se que a dieta MOS 1 proporcionou, de forma geral, maior peso médio e ganho de peso e melhor conversão alimentar das aves. Tais achados podem ser justificados por diferenças na cepa de levedura utilizada e nas condições de cultivo e de manufatura dos mananoligossacarídeos, porém, os mecanismos específicos pelos quais tais diferenças foram expressas não puderam ser determinados no presente estudo, mas é preciso que as consequências advindas de tais processos sejam consideradas quando da escolha do prebiótico a ser incluído na dieta de frangos de corte.

De modo geral, a melhora no desempenho das aves com inclusão de MOS às dietas pode ser resultado da modulação da microbiota intestinal das aves, uma vez que dietas com mananoligossacarídeos podem aumentar a população cecal de lactobacilos e de bifidobactérias e reduzir a concentração de Escherichia coli (BAURHOO et al., 2007ab). É importante ressaltar que lactobacilos secretam bacteriocinas (JIN et al., 1996) e bifidobactérias produzem ácidos orgânicos e outras substâncias bactericidas (GIBSON \& WANG, 1994) capazes de suprimir a colonização intestinal por microrganismos patogênicos e, consequentemente, proporcionar melhora na integridade da mucosa intestinal, no aproveitamento dos nutrientes das dietas e, por conseguinte, no desempenho das aves. Além disso, lactobacilos e bifidobactérias competem com microrganismos patogênicos por nutrientes e sítios de ligação, o que reduz a população de patógenos (ROLFE, 2000).

Outro ponto que deve ser considerado corresponde à capacidade dos mananoligossacarídeos em aumentar o número de células caliciformes na membrana do vilo (BAURHOO et al., 2007a; BAURHOO et al., 2009), as quais são especializadas em sintetizar e secretar mucinas e compostos glicoprotéicos que se ligam a microrganismos patogênicos e reduzem sua adesão à mucosa intestinal (BLOMBERG et al., 1993) . 
Tabela 3 - Consumo da dieta (CD), peso médio (PM), ganho de peso (GP) e conversão alimentar (CA) de frangos de corte submetidos às dietas experimentais.

\begin{tabular}{|c|c|c|c|c|c|c|}
\hline \multirow{2}{*}{$\begin{array}{l}\text { Característica } \\
\text { de desempenho }\end{array}$} & \multicolumn{4}{|c|}{ 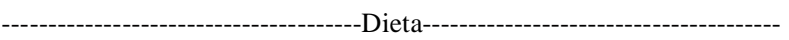 } & \multirow{2}{*}{ Probabilidade } & \multirow{2}{*}{$\mathrm{CV}(\%)$} \\
\hline & $\mathrm{CN}$ & $\mathrm{CP}$ & MOS 1 & MOS 2 & & \\
\hline $\mathrm{CD}, \mathrm{kg}$ & $1,218^{\mathrm{ab}}$ & $1,222^{\mathrm{a}}$ & $1,197^{\mathrm{ab}}$ & $1,191^{\mathrm{b}}$ & 0,038 & 1,95 \\
\hline $\mathrm{PM}, \mathrm{kg}$ & 0,922 & 0,948 & 0,925 & 0,922 & 0,146 & 2,73 \\
\hline $\mathrm{GP}, \mathrm{kg}$ & 0,878 & 0,904 & 0,881 & 0,887 & 0,170 & 2,41 \\
\hline $\mathrm{CA}, \mathrm{kg} / \mathrm{kg}$ & $1,386^{\mathrm{b}}$ & $1,349^{\mathrm{a}}$ & $1,358^{\mathrm{ab}}$ & $1,341^{\mathrm{a}}$ & 0,042 & 2,13 \\
\hline \multicolumn{7}{|c|}{-Fase de crescimento ( 22 a 33 dias de idade) ---- } \\
\hline $\mathrm{CD}, \mathrm{kg}$ & 1,735 & 1,675 & 1,686 & 1,711 & 0,434 & 3,89 \\
\hline $\mathrm{PM}, \mathrm{kg}$ & 1,889 & 1,936 & 1,881 & 1,903 & 0,298 & 2,80 \\
\hline $\mathrm{GP}, \mathrm{kg}$ & 0,967 & 0,988 & 0,956 & 0,982 & 0,716 & 5,19 \\
\hline $\mathrm{CA}, \mathrm{kg} / \mathrm{kg}$ & $1,797^{\mathrm{c}}$ & $1,695^{\mathrm{a}}$ & $1,765^{\text {bc }}$ & $1,744^{\mathrm{ab}}$ & 0,003 & 2,71 \\
\hline $\mathrm{CD}, \mathrm{kg}$ & 1,525 & 1,594 & 1,599 & 1,546 & 0,187 & 4,18 \\
\hline $\mathrm{PM}, \mathrm{kg}$ & $2,616^{\mathrm{b}}$ & $2,753^{\mathrm{a}}$ & $2,772^{\mathrm{a}}$ & $2,640^{\mathrm{b}}$ & 0,001 & 2,73 \\
\hline $\mathrm{GP}, \mathrm{kg}$ & $0,755^{\mathrm{b}}$ & $0,801^{\mathrm{b}}$ & $0,822^{\mathrm{a}}$ & $0,770^{\mathrm{b}}$ & $<0,001$ & 5,60 \\
\hline $\mathrm{CA}, \mathrm{kg} / \mathrm{kg}$ & $2,017^{\mathrm{b}}$ & $1,991^{\mathrm{b}}$ & $1,814^{\mathrm{a}}$ & $2,013^{\mathrm{b}}$ & 0,002 & 5,01 \\
\hline & & -Período & ção (1 a & idade) ---. & 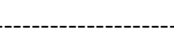 & ----- \\
\hline $\mathrm{CD}, \mathrm{kg}$ & 4,483 & 4,467 & 4,475 & 4,465 & 0,942 & 2,31 \\
\hline $\mathrm{PM}, \mathrm{kg}$ & $2,616^{\mathrm{b}}$ & $2,753^{\mathrm{a}}$ & $2,772^{\mathrm{a}}$ & $2,640^{\mathrm{b}}$ & 0,001 & 2,73 \\
\hline $\mathrm{GP}, \mathrm{kg}$ & $2,587^{\mathrm{b}}$ & $2,715^{\mathrm{a}}$ & $2,691^{a b}$ & $2,626^{\mathrm{ab}}$ & 0,030 & 3,47 \\
\hline $\mathrm{CA}, \mathrm{kg} / \mathrm{kg}$ & $1,734^{\mathrm{b}}$ & $1,645^{\mathrm{a}}$ & $1,664^{\mathrm{a}}$ & $1,701^{\mathrm{ab}}$ & 0,017 & 3,05 \\
\hline
\end{tabular}

${ }^{a, b}$ Médias com letras iguais nas linhas não diferem entre si pelo teste de Duncan $(p>0,05)$

A possível melhora na condição da microbiota intestinal pode traduzir-se em ganho no desempenho dos animais. Assim, de forma similar ao verificado no presente estudo, PARKS et al. (2001), em estudo com perus, eALBINO et al. (2006), ao avaliarem frangos de corte alimentados com prebióticos à base de mananoligossacarídeos, também verificaram efeitos positivos sobre o desempenho dos animais.

É importante salientar que as condições experimentais são imprescindíveis no comportamento dos dados e, portanto, na detecção de efeitos significativos. Assim, as respostas positivas observadas no presente estudo com a inclusão de MOS à dieta de frangos de corte podem ter sido evidenciadas pelo desafio sanitário à que as aves foram submetidas, pois se sabe que condições adversas podem exacerbar efeitos positivos de determinados aditivos (BAURHOO et al., 2007b).

De modo geral, foi possível constatar que a adição de mananoligossacarídeos à dieta de frangos de corte proporcionou benefícios sobre o desempenho das aves, sendo este similar ao apresentado pelo grupo $\mathrm{CP}$, o que sugere que o prebiótico possa ser uma alternativa efetiva ao uso de antibióticos como promotores de crescimento nas condições de desafio sanitário a que as aves foram submetidas.

\section{CONCLUSÃO}

Os mananoligossacarídeos podem ser utilizados como aditivo alternativo aos promotores de crescimento em dietas para frangos de corte, porém dependendo da fonte utilizada, esta pode acarretar em pequenas diferenças no desempenho das aves. Os mecanismos pelos quais ocorreu a ação dos mananoligossacarídeos não puderam ser determinados, visto que não foram observados efeitos conclusivos da influência destes sobre as características morfométricas do intestino das aves, sendo necessários mais estudos.

\section{AGRADECIMENTOS}

À Biorigin, pelo auxílio financeiro.

\section{COMITÊ DE ÉTICA E BEM-ESTAR ANIMAL DA FCAV}

Protocolo 006212/11.

\section{REFERÊNCIAS}

ALBINO, L.F.T. et al. Uso de prebióticos à base de mananoligossacarídeo em rações para frangos de corte. Revista 
Brasileira de Zootecnia, v.35, n.3, p.742-749, 2006. Disponível em: <http://www.scielo.br/pdf/\%0D/rbz/v35n3/ 30064.pdf $>$. Acesso em: 14 jan. 2011. doi: 10.1590/S151635982006000300015 .

BAURHOO, B. et al. Effects of purified lignin and mannan oligosaccharides on intestinal integrity and microbial populations in the ceca and litter of broiler chickens. Poultry Science, v.86, p.1070-1078, 2007a. Disponível em: <http://ps.fass.org/ cgi/reprint/86/6/1070>. Acesso em: 14 jan. 2011.

BAURHOO, B. et al. Cecal populations of lactobacilli and bifidobacteria and Escherichia coli populations after in vivo Escherichia coli challenge in birds fed diets with purified lignin or mannanoligosaccharides. Poultry Science, v.86, p.2509-2516, 2007b. Disponível em: <http://ps.fass.org/cgi/reprint/86/12/ 2509 ? maxtoshow $=$ \&hits $=10 \&$ RESULTFORMAT $=$ \&author $1=$ ba urhoo\&searchid=1\&FIRSTINDEX $=0 \&$ sortspec $=$ relevance $\&$ reso urcetype $=$ HWCIT $>$. Acesso em: 14 jan. 2011. doi: 10.3382/ ps.2007-00136

BAURHOO, B. et al. Purified cell wall of Saccharomyces cerevisiae increases protection against intestinal pathogens in broiler chickens. International Journal of Poultry Science, v.8, n.2, p.133-137, 2009. Disponível em: <http://docsdrive.com/ pdfs/ansinet/ijps/2009/133-137.pdf>. Acesso em: 14 jan. 2011.

BEHMER, A.O. et al. Manual de técnicas para histologia e patológica. São Paulo: EUSPE, 1976. 239p.

BLOMBERG, L. et al. Piglet ileal mucus contains protein and glycolipid (Galactosylceramide) receptors specific for Escherichia coli K88 Fimbriae. Infection and Immunity, v.61, n.6, p.2526-2531, 1993. Disponível em: <http:// iai.asm.org/cgi/reprint/61/6/2526>. Acesso em: 06 mar. 2011.

FAIRCHILD, A.S. et al. Effects of hen age, Bio-Mos ${ }^{\circledR}$ and Flavomycin ${ }^{\circledR}$ on poult susceptibility to oral Escherichia coli challenge. Poultry Science, v.80, p.562-571, 2001. Disponível em: <http://ps.fass.org/cgi/reprint/80/5/562〉. Acesso em: 06 mar. 2011.

GARTNER, L.P.; HIATT, J.L. Color textbook of histology. 2.ed. Baltimore: Saunders, 2001. 592p.

GIBSON, G.R.; ROBERFROID, M.B. Dietary modulation of the human colonic microbiota: Introducing the concept of prebiotics. Journal of Nutrition, v.125, n.6, p.1401-1412, 1995. Disponível em: <http://jn.nutrition.org/content/125/6/ 1401.full.pdf+html>. Acesso em: 20 jan. 2011.

GIBSON, G.R.; WANG, X. Regulatory effects of bifidobacteria on the growth of other colonic bacteria. Journal of Applied Microbiology, v.77, n.4, p.412-420, 1994. Disponível em: <http://onlinelibrary.wiley.com/doi/10.1111/j.1365- 2672.1994.tb03443.x/abstract>. Acesso em: 22 jan. 2011. doi: $10.1111 / \mathrm{j} .1365-2672.1994 . t b 03443 . x$.

JIN, L.Z. et al. Antagonistic effects of intestinal Lactobacillus isolates on pathogens of chicken. Letters in Applied Microbiology, v.23, n.2, p.67-71, 1996. Disponível em: <http://onlinelibrary.wiley.com/doi/10.1111/j.1472765X.1996.tb00032.x/abstract>. Acesso em: 24 jan. 2011. doi: $10.1111 / \mathrm{j} .1472-765 X .1996 . t b 00032 . \mathrm{x}$

BOLELI, I.C. et al. Estrutura funcional do trato digestório. In: MACARI, M. et al. Fisiologia aviária aplicada a frangos de corte. Jaboticabal: FUNEP/UNESP, 2002. p.75-95.

PARKS, C.W. et al. The effect of mannanoligosaccharides, bambermycins, and virginiamycin on performance of large white male market turkeys. Poultry Science, v.80, p.718-723, 2001. Disponível em: 〈http://ps.fass.org/cgi/reprint/80/6/718>. Acesso em: 22 jan. 2011.

PELICANO, E.R.L. et al. Intestinal mucosa development in broiler chickens fed natural growth promoters. Revista Brasileira de Ciência Avícola, v.7, n.4, p.221-229, 2005. Disponível em: 〈http://www.scielo.br/pdf/rbca/v7n4/28744.pdf>. Acesso em: 20 jan. 2011. doi: 10.1590/S1516$635 \times 2005000400005$.

RASBAND, W.S. Image J. 2004. National Institutes of Health, Bethesda, Maryland, USA. Disponível em: <http.// rsb.info.nih.gov/ij/>. Acesso em: 20 mar. 2008.

ROLFE, R.D. The role of probiotic cultures in the control of gastrointestinal health. Journal of Nutrition, v.130, p.396S402S, 2000. Disponível em: <http://jn.nutrition.org/content/ 130/2/396.short>. Acesso em: 06 mar. 2011.

ROSTAGNO, H.S. et al. Tabelas brasileiras para aves e suínos: composição de alimentos e exigências nutricionais. 2.ed. Viçosa, MG: Universidade Federal de Viçosa, 2005. 186p.

SAKOMURA, N.K.; ROSTAGNO, H.S. Métodos de pesquisa em nutrição de monogástricos. Jaboticabal: FUNEP, 2007. 283p.

SANTIN, E. et al. Performance and intestinal mucosa development of broiler chickens fed diets containing Saccharomyces cerevisiae cell wall. Journal of Applied Poultry Research, v.10, p.236-244, 2001. Disponível em: <http:// japr.fass.org/cgi/reprint/10/3/236>. Acesso em: 24 jan. 2011.

SAS INSTITUTE. SAS/STAT: user's guide. version 8.ed. Cary, NC, 2008. 28p.

SPRING, P. et al. The effects of dietary mannanoligosaccharides on cecal parameters and the concentrations of enteric bacteria in the ceca of salmonella-challenged broiler chicks. Poultry Science, v.79, p.205-211, 2000. Disponível em: <http:// ps.fass.org/cgi/reprint/79/2/205>. Acesso em: 23 jan. 2011. 